\title{
ESTIMATIVA DE COEFICIENTES DE REPETIBILIDADE PARA MANCHA OCULAR EM CLONES DE PENNISETUM"
}

\author{
ESTIMATIVE OF REPEATABILITY COEFFICIENTS, FOR LEAF SPOT OCURRENCE IN \\ PENNISETUM SP. CLONES
}

\author{
Oliveira, T.N., ${ }^{1}$ Santos, M.V.F. ${ }^{2 *}$, Lira, M.A. ${ }^{3}$, Mello, A.C.L. ${ }^{2}$, Ferreira, R.L.C. ${ }^{2}$, Lira Júnior, M.A. ${ }^{2}$ \\ e Silva, N.G.M. ${ }^{2}$
}

\begin{abstract}
${ }^{1}$ Instituto Federal do Sertão Pernambucano. Campus Floresta. Brasil. tatiana.neres@ifsertao-pe.edu.br 2Universidade Federal de Pernanbuco. UFRPE. Recife-PE. Brasil. *mercia@dz.ufrpe.br 3IPA. São Paulo-SP. Brasil.
\end{abstract}

\section{PalaVRas chave adicionais}

Capim-elefante. Helminthosporium sp. Melhoramento de forrageiras. Variabilidade genética.

\section{RESUMO}

O trabalho foi realizado na Estação Experimental de Itambé, do Instituto Agronômico de Pernambuco-IPA, e objetivou obter estimativas de parâmetros genéticos e de coeficientes de repetibilidade, sob diferentes métodos, da variável mancha ocular em clones de Pennisetum. Foram avaliados 16 clones de Pennisetum em delineamento de blocos ao acaso, com cinco repetições, no período de março de 2004 a maio de 2005 , totalizando sete avaliações. Os coeficientes de repetibilidade foram estimados por: análise de variância, componentes principais - matriz de correlação, componentes principais - matriz de covariância e análise estrutural - matriz de correlação. O valor máximo da herdabilidade para mancha ocular foi de $95 \%$. Os coeficientes de repetibilidade estimados pelos quatro métodos variaram de 0,75 a 0,78 . As sete avaliações foram suficientes para obter coeficiente de determinação de 0,95 para todos os métodos avaliados. Não foi observada diferença entre os métodos avaliados.

\section{SUMMARY}

The work was conducted at the Itambé Experimental Station, of the Pernambuco State Agricultural Research Enterprise, to obtain genetic

"Realizado pelo convênio IPA-UFRPE, parte da Tese apresentada ao PDIZ pela primeira autora.

Recibido: 5-5-09. Aceptado: 12-5-10.

\section{AdDITIONAL KEYWORDS}

Elephant-grass. Helminthosporium sp. Forage breeding. Genetic variability.

parameters estimates and repeatability coefficient, under different methods, for leaf spot in Pennisetum clones. Sixteen Pennisetum clones were evaluated on a randomized block design, with five replicates, from March 2004 to May 2005, totaling seven evaluations. Repeatability coefficients were estimated by: analysis of variance, principal components - correlation matrix, principal components - covariance matrix, and structural analysis - correlation matrix. Maximum heritability for leaf spot was $95 \%$. Repeatability coefficients the four methods ranged from 0.75 to 0.78 among. Seven evaluations were able to obtain determination a coefficient of 0.95 for all evaluated methods. No differences were observed among methods.

\section{INTRODUÇÃO}

Uma das dificuldades encontradas pelos programas de seleção e avaliação é a determinação do número de avaliações necessárias (cortes ou épocas de pastejo) para estimar as diferenças entre genótipos avaliados. Normalmente o processo envolve grande número de experimentos, com várias etapas e avaliação de diferentes características, significando o emprego de considerável mão-de-obra e tempo. Como alternativa para superar tais limitações, a estimativa 
do coeficiente de repetibilidade ( $\mathrm{r}$ ) pode ser usada para reduzir o número de avaliações (Farias Neto et al., 2004).

Por meio da estimativa desse coeficiente é possível determinar quantas medições deverão ser realizadas em cada indivíduo para que a avaliação e/ou caracterização fenotípica seja feita com precisão (Costa, 2003). Adicionalmente, a repetibilidade expressa o valor máximo que a herdabilidade pode atingir, pois expressa a variância fenotípica que é atribuída às diferenças genéticas, confundidas com os efeitos permanentes que atuam no genótipo.

Segundo Cruz e Regazzi (2001), o coeficiente de repetibilidade de uma característica pode ser conceituado, estatisticamente, como sendo a correlação entre as medidas em um mesmo indivíduo, cujas avaliações foram repetidas no tempo ou espaço. A repetibilidade expressa a proporção da variância total, que é devida às variações proporcionadas pelo genótipo e às alterações permanentes atribuídas ao ambiente comum. O número de medições necessárias para a previsão do valor real do indivíduo é aquele em que, os efeitos temporários do ambiente sobre o caráter tendem a se cancelar.

Há diversos métodos propostos para estimativa dos coeficientes de repetibilidade. Segundo Cargnelutti Filho et al. (2004), métodos para a obtenção de estimativas de coeficiente de repetibilidade, como o da análise de variância, dos componentes principais e o da análise estrutural, têm sido usados em culturas perenes, como o capimelefante. Cruz e Regazzi (2001) obtiveram estimativas do coeficiente de repetibilidade utilizando métodos da análise de variância. Componentes principais, conforme Rutledge (1974), é o método mais adequado para estimar coeficiente de repetibilidade quando, ao longo das avaliações, os genótipos apresentam comportamento cíclico, em relação ao caráter estudado. Análise estrutural, método proposto por Mansour et al. (1981), apresenta diferenças apenas conceituais em relação ao método dos com- ponentes principais e, segundo os autores, é mais adequado quando as variâncias nas diversas medições não são homogêneas. Silva (2006), avaliando genótipos de Pennisetum, utilizou o método da análise de variância para estimar coeficientes de repetibilidade para a variável susceptibilidade a doenças, observando valores de 0 a 1 .

Valores altos de estimativas de repetibilidade para determinado caráter indicam que é viável predizer o valor real do indivíduo utilizando-se um número relativamente pequeno de medições (Cruze Regazzi, 1997), sendo que ocorre o inverso quando a repetibilidade é baixa. Ao se escolher um genótipo, conforme relatos de Cruz e Regazzi (2001), espera-se que sua superioridade inicial perdure toda a sua vida. A veracidade dessa expectativa poderá ser comprovada pelo coeficiente de repetibilidade, que permite determinar o número de observações fenotípicas que devem ser realizadas, com um mínimo de custo e mão-de-obra.

No que diz respeito a incidência de doenças no gênero Pennisetum, tem-se observado que o fungo Helminthosporium é um dos principais causadores de algumas enfermidades, como a mancha ocular em capim-elefante, conforme observado por Reis et al. (1997).

O Helminthosporium é um tipo de fungo que causa manchas foliares severas em várias gramíneas. Os sintomas da maioria das plantas consistem em grande quantidade de lesões, variando de elípticas a alongadas, de coloração escura, como observado em Paspalum atratum (Anjos et al., 2004). Os danos observados nesta forrageira foram a redução da área fotossintética e perdas de produção de massa verde e, conseqüentemente, de sementes nos campos infectados por esse fungo.

A ocorrência do fungo Helminthosporium é comum em genótipos de capimelefante sob corte e pastejo na Zona da Mata de Pernambuco. Oliveira et al. (2007) observaram que os genótipos mais infestados tiveram a produção de matéria seca 


\section{COEFICIENTES DE REPETIBILIDADE PARA MANCHA FOLIAR EM PENNISETUM}

comprometida, apresentando produção inferior aos genótipos menos infestados pelo fungo, evidenciando os efeitos negativos do Helminthosporium.

Assim, o objetivo deste trabalho foi estimar coeficientes de repetibilidade para ocorrência da mancha ocular em clones de Pennisetum, na Zona da Mata de Pernambuco.

\section{MATERIALEMÉTODOS}

O experimento foi realizado na Estação Experimental de Itambé, do Instituto Agronômico de Pernambuco-IPA, no período de agosto de 2003 a janeiro de 2005.

O município de Itambé localiza-se nas coordenadas geográficas $7^{\circ} 25^{\prime} 00^{\prime \prime} \mathrm{de}$ latitude Sul e $35^{\circ} 06^{\prime} 00^{\prime \prime}$ de longitude Oeste, na microrregião fisiográfica da Mata Seca de Pernambuco, a $190 \mathrm{~m}$ de altitude. A precipitação média anual é de aproximadamente $1200 \mathrm{~mm}$, com temperatura média anual de $26^{\circ} \mathrm{C}$ (CPRH, 2003), sendo observadas médias de $1501 \mathrm{~mm}, 1704 \mathrm{mme} 1174 \mathrm{~mm}$ para os anos de 2003, 2004 e 2005, respectivamente (tabela I).

$O$ resultado da análise de solo revelou $\mathrm{pH}\left(\mathrm{H}_{2} \mathrm{O}\right)=5,4 ; \mathrm{P}$ disponível $($ Mehlich-1 $)=29$ $\mathrm{mg} / \mathrm{kg} ; \mathrm{Ca}=2,69 \mathrm{cmol}_{\mathrm{c}} / \mathrm{dm}^{3} ; \mathrm{Mg}=1,20 \mathrm{cmol}_{\mathrm{c}} /$ $\mathrm{dm}^{3} ; \mathrm{K}=0,21 \mathrm{cmol} / \mathrm{dm}^{3} ; \mathrm{Al}=0,60 \mathrm{cmol}^{2} / \mathrm{dm}^{3}$; $\mathrm{H}=9,98 \mathrm{cmol} / \mathrm{dm}^{3} ; \mathrm{S}=2,45 \mathrm{cmol} / \mathrm{dm}^{3} ; \mathrm{CTC}=$ $16,8 \mathrm{cmol}_{\mathrm{c}} / \mathrm{dm}^{3} ; \mathrm{V}=25,5 \%$ na camada de 0 a $20 \mathrm{~cm}$ de profundidade, a qual recomendou a utilização de 1,5 t/ha de calcário, que foi aplicado após o preparo do solo.

O plantio foi realizado em agosto de 2003 por meio vegetativo, em sulcos espaçados de um metro e profundidade de $20 \mathrm{~cm}$. A adubação nitrogenada foi realizada utilizando-se $200 \mathrm{~kg} \mathrm{ha}^{-1}$ de $\mathrm{N}$ na forma de uréia, sendo parcelada em duas aplicações, uma por ocasião do plantio e a outra, após o corte de uniformização, realizado 240 dias após o plantio.

O delineamento experimental foi o de blocos ao acaso com parcelas subdivididas e cinco repetições. Os genótipos foram considerados como a parcela principal e as subparcelas, as épocas de avaliação. A área das parcelas foi de $5 \mathrm{~m} \mathrm{x} 5 \mathrm{~m}$ com espaçamento de um metro entre linhas e dois metros entre blocos e área útil de $4 \mathrm{~m} \mathrm{x} 4 \mathrm{~m}$, desconsiderando uma $0,25 \mathrm{~m}$ em cada extremidade.

Foram utilizados 16 genótipos de Pennisetum, incluindo um híbrido triplóide, o HV 241, originários dos programas de melhoramento do IPA/UFRPE e EMBRAPA (tabela II ). Vale ressaltar que o presente trabalho refere-se a fase 2 do programa de melhoramento de forrageiras proposto por Valle e Souza (1995).

Os genótipos foram avaliados em intervalos de pastejo de 42 dias, no período chuvoso, e 90 dias no período seco, com um dia de ocupação e altura média do resíduo de $40 \mathrm{~cm}$, perfazendo um total de sete avaliações (medições). As avaliações foram realizadas em março/2004, maio/2004, junho/ 2004,julho/2004, agosto/2004, janeiro/2005

Tabela I. Dados de precipitação ( $\mathrm{mm}$ ) obtidos na Estação Experimental de Itambé, durante o período experimental. (Rainfall data $(\mathrm{mm})$ at the Itambé-PE Experimental Station, during the experimental period)

\begin{tabular}{lccc}
\hline Mês & Ano & \\
& 2003 & 2004 & 2005 \\
\hline Janeiro & 38,9 & 242,6 & 4,0 \\
Fevereiro & 209,0 & 230,8 & 29,6 \\
Março & 165,4 & 74,4 & 70,0 \\
Abril & 82,0 & 193,2 & 49,2 \\
Maio & 143,2 & 209,4 & 216,0 \\
Junho & 353,4 & 297,0 & 463,0 \\
Julho & 167,6 & 299,0 & 77,8 \\
Agosto & 73,6 & 72,6 & 171,6 \\
Setembro & 72,0 & 50,8 & 28,8 \\
Outubro & 48,2 & 9,0 & 24,8 \\
Novembro & 86,6 & 7,0 & 11,0 \\
Dezembro & 71,6 & 10,0 & 22,0 \\
Anual & 1501,5 & 1704,5 & 1174,4
\end{tabular}

Fonte: Estação Experimental de Itambé-IPA. 
Tabela II. Origem e genealogia dos genótipos de Pennisetum avaliados. (Pennisetum genotypes origin and pedigree).

\begin{tabular}{|c|c|c|}
\hline Genótipos & Progenitores & Origem \\
\hline Mineirão & - & Variedade comercial \\
\hline P18 & IPA-2000 - Taiwan A 25 & Programa de melhoramento do IPA/UFRPE \\
\hline P25 & IPA-2000 - Pusa Napier 1 & Programa de melhoramento do IPA/UFRPE \\
\hline P27 & IPA-2000 - Pusa Napier 1 & Programa de melhoramento do IPA/UFRPE \\
\hline P28 & IPA-2000 - Pusa Napier 1 & Programa de melhoramento do IPA/UFRPE \\
\hline P31 & IPA-2000 - Pusa Napier 1 & Programa de melhoramento do IPA/UFRPE \\
\hline P32 & IPA-2000 - Pusa Napier 1 & Programa de melhoramento do IPA/UFRPE \\
\hline P33 & IPA-2000 - Pusa Napier 1 & Programa de melhoramento do IPA/UFRPE \\
\hline P35 & IPA-2000 - SEA & Programa de melhoramento do IPA/UFRPE \\
\hline P36 & IPA-2000 - SEA & Programa de melhoramento do IPA/UFRPE \\
\hline P37 & IPA-2000 - SEA & Programa de melhoramento do IPA/UFRPE \\
\hline P80 & IPA-2000 - Roxo de Botucatu & Programa de melhoramento do IPA/UFRPE \\
\hline 93F41.1 & Clone 6 RENACE & Embrapa Gado de Leite \\
\hline HV 241 & Híbrido milheto $x$ capim-elefante & Programa de melhoramento do IPA/UFRPE \\
\hline P73 & IPA-2000 - Gigante de Pinda & Programa de melhoramento do IPA/UFRPE \\
\hline Pioneiro & - & Embrapa Gado de Leite \\
\hline
\end{tabular}

e maio/2005. Foi estabelecida uma escala de notas para avaliação da ocorrência de mancha ocular nos genótipos de capim-elefante, conforme a ocorrência de fungos do gênero Helminthosporium, sendo $1=$ baixa incidência; $2=$ média incidência; $3=$ alta incidência e $4=$ altíssima incidência.

Amostras de folhas dos genótipos foram colhidas e encaminhadas para o Laboratório de Fitossanidade da Universidade Federal Rural de Pernambuco para identificação do agente causador.

Para estimativa dos coeficientes de repetibilidade foram utilizados os seguintes procedimentos: análise de variância; componentes principais por meio da matriz de correlação intraclasse; componentes principais pela matriz de variância e covariância fenotípica, e análise estrutural por meio da matriz de correlação, descritos por Cruz e Regazzi (2001).

O método da análise de variância estimou o coeficiente de repetibilidade por meio da correlação intraclasse obtida da análise de variância, considerando o modelo estatístico reduzido, com base em média de avaliações e genótipos:

$$
\mathrm{Y}_{\mathrm{ik}}=\mu+\mathrm{g}_{\mathrm{i}}+\mathrm{c}_{\mathrm{k}}+\varepsilon_{\mathrm{ik}}
$$

Em que:

$\mathrm{Y}_{\mathrm{i} \mathrm{k}}=$ valor médio observado, relativo ao i-ésimo genótipo, na k-ésima avaliação,

$\mu=$ média geral,

$g_{i}=$ efeito aleatório do i-ésimo genótipo sob influência do ambiente permanente $(i=1, \ldots, p$; $\mathrm{p}=16$ ),

$c_{k}=$ efeito fixo do ambiente temporário na k-ésima avaliação $(k=1, \ldots, n ; n=7)$,

$\varepsilon_{\mathrm{ik}}=$ erro experimental estabelecido pelos efeitos temporários do ambiente na k-ésima avaliação, do i-ésimo genótipo.

Nesses efeitos são incluídas, em uma única fonte, denotada por resíduo, todas as demais fontes de variação não consideradas no modelo.

O coeficiente de repetibilidade $r$ foi obtido por:

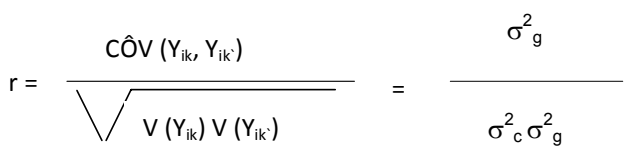


em que:

$\sigma^{2}=(Q M G-Q M E) / c$,

$\sigma_{\mathrm{e}}^{\mathrm{g}}=\mathrm{QME}$.

Por meio do método dos componentes principais se estimou o coeficiente de repetibilidade de duas maneiras: a primeira por meio da matriz de correlação e a outra por meio da matriz de variâncias e covariâncias fenotípicas.

O coeficiente de repetibilidade foi estimado pelo método dos componentes principais - matriz de correlação a partir de uma matriz de correlação entre os genótipos em cada par de avaliações. Nessa matriz, são determinados os autovalores $(\lambda)$ e os autovetores $(\alpha)$ normalizados de R. O autovetor cujos elementos apresentam mesmo sinal e magnitudes próximas é aquele que expressa a tendência de os genótipos manterem suas posições relativas nos vários intervalos de avaliação. O estimador do coeficiente de repetibilidade é a proporção do autovalor associado a esse autovetor, que é expresso por:

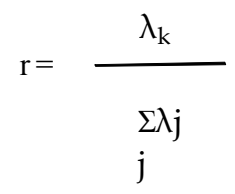

sendo:

$j=1,2, \ldots, n$,

$\mathrm{n}=$ número de cortes avaliados,

$\lambda_{\mathrm{k}}=$ autovalor associado ao autovetor, cujos elementos têm mesmo sinal e magnitude semelhante.

Rutledge (1974), relatou que $\lambda_{k}$ é influenciado pelo número de medições dos indivíduos; assim, o estimador $\mathrm{r}$ torna-se mais adequado à estimação do coeficiente de repetibilidade, que é obtido por:

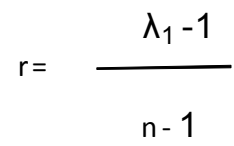

em que:

$\lambda_{1}=1+(\lambda-1) p \lambda_{1}$ é o autovalor de $\mathrm{R}$ associado ao autovetor cujos elementos têm mesmo sinal e magnitude semelhantes,

$\mathrm{n}=$ número de medições

$\mathrm{p}=$ número de genótipos .

O coeficiente de repetibilidade foi estimado com o uso do método dos componentes principais por meio da aplicação da matriz de variâncias e covariâncias fenotípicas (I').

O estimador do coeficiente de repetibilidade foi obtido por:

$$
r=\frac{\lambda_{1}-\sigma_{y}^{2}}{\sigma_{y}^{2}(n-1)}
$$

em que:

$\lambda_{1}=$ é o autovalor $r$ associado ao autovetor cujos elementos têm mesmo sinal e magnitude semelhantes,

$\sigma_{y}^{2}=\sigma_{g}^{2}+\sigma_{e}^{2}$

$\mathrm{n}=$ número de avaliações.

A análise estrutural foi utilizada conforme metodologia proposta por Mansour et al. (1981). Nesse método, considera-se R a matriz paramétrica de correlações entre os genótipos em cada par de avaliações e $\mathrm{R}$ o seu estimador.

Um estimador do coeficiente de repetibilidade com base na análise estrutural foi expresso por:

$\alpha^{\prime} \mathrm{R} \alpha-1$

$r=$

$n-1$

em que:

$\alpha$ 'é o autovetor com elementos paramétricos, associados ao maior autovalor da matriz de correlação uniforme $\mathrm{R}$, que é dado por:

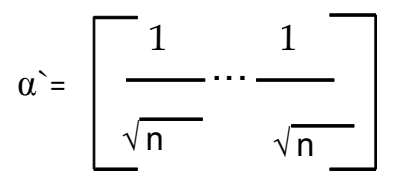


O número mínimo de medições necessárias para predizer o valor real dos genótipos foi obtido com base em um coeficiente de determinação $\left(\mathrm{R}^{2}\right)$ pré-estabelecido (tabela III), calculado por Cruz e Regazzi (1997).

Foi estimado o coeficiente de determinação para a ocorrência de Helminthosporium , com base na média de $n$ avaliações $(n=7)$ e na estimativa dos coeficientes de repetibilidade obtidos de acordo com um dos diferentes métodos utilizados, pela seguinte expressão:

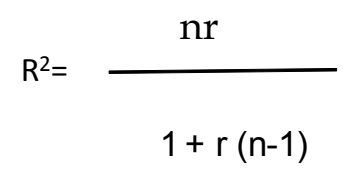

em que:

$\mathrm{n}=$ número de avaliações $(\mathrm{n}=7)$,

$r=$ coeficiente de repetibilidade.

As análises estatísticas foram realizadas com o uso do Programa computacional Genes (Cruz, 2004), para estimativa dos coeficientes de repetibilidade. Os dados de ocorrência de mancha ocular, considerando todas as avaliações, foram avaliadas pelo

Tabela III. Número de medições para determinação de $R^{2}$ pré-estabelecidos, conforme diferentes métodos. (Number of measurements for pré-established $\mathrm{R}^{2}$, according to different methods).

\begin{tabular}{ccccc}
\hline $\mathrm{R}^{2}$ & $\mathrm{~A}$ & $\mathrm{CPcv}$ & $\mathrm{CPcr}$ & $\mathrm{AEcr}$ \\
\hline 0,80 & 1,32 & 1,10 & 1,28 & 1,31 \\
0,85 & 1,87 & 1,56 & 1,82 & 1,86 \\
0,90 & 2,97 & 2,47 & 2,88 & 2,96 \\
0,95 & 6,27 & 5,22 & 6,09 & 6,25 \\
0,99 & 32,68 & 27,23 & 31,74 & 32,57 \\
\hline
\end{tabular}

A: Anova; CPcv: Componentes principais (covariância); CPcr: Componentes principais (correlação); AEcr: Análise estrutural (correlação).

Adaptado de Cruz e Regazzi (1997). pacote estatístico SAS (Statistical Analysis System), versão 8.0 (SAS Institute, 1999) e as médias comparadas pelo teste de Tukey a $5 \%$.

\section{RESULTADOSEDISCUSSÃO}

Os efeitos de genótipos e medições foram significativos $(\mathrm{p}<0,05)$ para a mancha ocular (tabela IV). Tal resultado indica a existência de variabilidade genética, o que possibilita a identificação de genótipos mais resistentes à incidência de doenças. A interação genótipos x medições foi significativa $(\mathrm{p}<0,05)$, mostrando que o comportamento dos genótipos diferiu em relação às diferentes medições (avaliações). Segundo Daher et al. (2004), tal fato indica uma grande heterogeneidade de condições ambientais, traduzindo-se na ocorrência de períodos considerados favoráveis e desfavoráveis, geralmente ligados às épocas das águas e da seca, aliados ao desempenho irregular dos clones ao longo dos períodos, acarretando ocorrência de interação genótipos $\mathrm{x}$ ambientes.

Isso pode ser explicado pelo fato de que as avaliações foram feitas num longo período (março de 2004 a maio de 2005), ocorrendo diferenças climáticas entre ellas, como períodos de maior precipitação (tabela I), que favoreceu maior desenvolvimento do fungo Helminthosporium, causador da mancha ocular. Evidenciou-se que a incidência de doenças foi afetada pelas condições climáticas que se estabeleceram no período de cada avaliação (tabela V) e que os genótipos contavam com sensibilidade diferente para responder a essas variações ambientais. Estes resultados eram esperados, visto que este caráter, conforme relatos de Pereira et al. (1998), é intensamente influenciado pelos efeitos genéticos (variação entre tratamentos) e ambientais (variação entre datas de avaliação). Silva (2006), trabalhando com genótipos de Pennisetum sob corte na Zona da Mata de Pernambuco, também observou variação dos materiais quanto a

Archivos de zootecnia vol. 60, núm. 231, p. 802. 
Tabela IV. Resumo da análise de variância e estimativa dos parâmetros genéticos e ambientais da ocorrência de mancha ocular em 16 genótipos de Pennisetum sp. (Summary of the analysis of variance and estimates of the genetic and the environmental parameters of the leaf spot in 16 Pennisetum sp. genotypes).

\begin{tabular}{lccc}
\hline Fonte de variação & $\mathrm{GL}$ & $\mathrm{QM}$ & $\mathrm{F}$ \\
\hline Bloco & 4 & 10,25 & \\
Genótipo & 15 & 14,90 & $19,31^{* *}$ \\
Erro a & 60 & 0,78 & $31,92^{* *}$ \\
Medições & 6 & 10,01 & $2,14^{* *}$ \\
Genótipo x medições & 90 & 0,67 & \\
Erro b & 384 & 0,31 & - \\
& & & \\
Média & - & 2,09 & - \\
& & & - \\
Componente de variância genotípica ${ }^{1}\left(\sigma^{2}\right)$ & - & 0,40 & - \\
Componente de variabilidade das medições $\left(\phi_{g}\right)$ & - & 0,12 & - \\
Valor máximo da herdabilidade $-\mathrm{h}^{2}(\%)$ & - & 95,0 & - \\
Coeficiente de variação genética $\mathrm{CV}_{\mathrm{g}}(\%)$ & - & 30,0 & \\
Coeficiente de variação experimental $\mathrm{CV}_{\text {Ea }}$ & - & 26,70 & \\
\hline
\end{tabular}

${ }^{* *} p<0,01 ;{ }^{1}$ Componente de variância genotípica confundido com os efeitos permanentes dos ambientes.

susceptibilidade à doenças. Foi observada maior incidência do fungo Helminthosporium em maio de 2003, período de maior ocorrência de chuvas.

Os genótipos que apresentaram maiores notas para incidência de mancha ocular (tabela V), indicando maior susceptibilidade ao fungo Helminthosporium, foram o Taiwan A25 P 18(3,41), SEA P 36 (3,29), SEA P $37(3,02)$ e Pioneiro $(2,57)$. Considerando os meses de avaliação, os períodos de maior incidência da mancha ocular ocorreram nas avaliações realizadas em 03/2004 (2,67) e 01/ 2005 (2,37). Esses períodos não foram os que apresentaram maior precipitação, mas a maior ocorrência da mancha ocular em março de 2004, pode ser reflexo da precipitação do mês de fevereiro $(230,8 \mathrm{~mm})$. Já a alta incidência ocorrida no mês de janeiro de 2005 , pode ser explicada pelo fato de que o ataque do fungo às plantas não foi controlado durante a execução do experimento, em função disso, no final das avaliações experimentais a incidência do fungo já estava alta, e a avaliação realizada em janeiro de 2005 representou a penúltima do período experimental.

A estimativa do coeficiente de variação genético para mancha ocular foi de $30,0 \%$ (tabela IV). O coeficiente de variação experimental $\mathrm{CV}_{\mathrm{Ea}}$ no qual foram alocados os genótipos e que serve de parâmetro para verificar a precisão experimental da variação genética, foi de 26,70\%. Daher et al. (2004) ressaltam que coeficiente de variação experimental acompanhado de elevado valor de coeficiente de variação genético $\left(\mathrm{CV}_{\mathrm{g}}\right)$, como observado no presente trabalho, reduz a magnitude do efeito ambiental que atua sobre os genótipos. Segundo Shimoya et al. (2002), as estimativas do coeficiente de variação genética $\left(\mathrm{CV}_{\mathrm{g}}\right)$ são importantes num programa de melhoramento, pois indicam a amplitude de variação genética de uma característica.

A estimativa do valor máximo da herdabilidade foi considerada satisfatória $(95,0 \%)$, o que torna viável a seleção de 
OLIVEIRA, SANTOS, LIRA, MELLO, FERREIRA, LIRA JÚNIORE SILVA

Tabela $V$. Ocorrência de mancha ocular ${ }^{l}$ em clones de Pennisetum sp. sob pastejo. (Occurrence of eye stain in clones of Pennisetum sp. under pasture).

\begin{tabular}{|c|c|c|c|c|c|c|c|c|}
\hline \multirow[t]{2}{*}{ Tratamentos } & \multicolumn{8}{|c|}{ Avaliação } \\
\hline & $03 / 2004$ & $05 / 2004$ & $06 / 2004$ & $07 / 2004$ & $08 / 2004$ & $01 / 2005$ & $05 / 2005$ & Média \\
\hline Mineirão & 1,20 & 1,00 & 1,00 & 1,00 & 1,00 & 1,20 & 1,40 & $1,10^{g}$ \\
\hline Taiwan A 25 P 18 & 3,80 & 3,00 & 2,80 & 3,80 & 3,40 & 3,20 & 3,60 & $3,41^{a}$ \\
\hline Pusa Napier 1 P 25 & 2,80 & 2,00 & 1,40 & 1,40 & 1,60 & 2,80 & 2,40 & $2,09^{d}$ \\
\hline Pusa Napier 1 P 27 & 3,00 & 2,00 & 1,20 & 1,40 & 1,20 & 2,00 & 1,60 & $1,80^{\text {de }}$ \\
\hline Pusa Napier 1 P 28 & 2,40 & 2,00 & 1,20 & 1,40 & 1,40 & 2,80 & 2,00 & $1,98^{\text {de }}$ \\
\hline Pusa Napier 1 P 31 & 2,40 & 2,20 & 1,20 & 1,40 & 2,00 & 2,40 & 1,60 & $1,94^{\text {de }}$ \\
\hline Pusa Napier 1 P 32 & 2,40 & 2,20 & 1,20 & 1,80 & 1,60 & 2,60 & 2,00 & $1,98^{\text {de }}$ \\
\hline Pusa Napier 1 P 33 & 2,20 & 2,00 & 1,00 & 1,40 & 1,80 & 2,40 & 2,00 & $1,89^{\text {de }}$ \\
\hline SEA P 35 & 3,60 & 2,20 & 1,60 & 1,80 & 1,80 & 2,40 & 2,00 & $2,09^{\text {cd }}$ \\
\hline SEA P 36 & 4,00 & 3,40 & 3,20 & 3,40 & 3,20 & 2,60 & 3,20 & $3,29^{a}$ \\
\hline SEA P 37 & 3,80 & 2,80 & 3,00 & 3,20 & 2,80 & 2,80 & 2,40 & $3,02^{\mathrm{ab}}$ \\
\hline Roxo Botucatu P 80 & 1,80 & 1,20 & 1,00 & 1,60 & 1,40 & 2,20 & 1,60 & $1,48^{\text {ef }}$ \\
\hline RENACE 93F41.1 & 2,40 & 1,60 & 1,60 & 2,00 & 1,80 & 1,60 & 1,40 & $1,72^{\mathrm{de}}$ \\
\hline HV 241 & 2,40 & 1,00 & 1,20 & 1,80 & 2,00 & 2,80 & 2,00 & $1,90^{\text {de }}$ \\
\hline Gigante Pinda P 73 & 1,40 & 1,40 & 1,00 & 1,00 & 1,40 & 1,40 & 1,60 & $1,28^{f g}$ \\
\hline Pioneiro & 3,20 & 2,00 & 1,60 & 2,40 & 2,60 & 2,80 & 3,60 & $2,57^{\mathrm{bc}}$ \\
\hline Média & $2,67^{A}$ & $2,00^{\mathrm{CD}}$ & $1,56^{\mathrm{E}}$ & $1,92^{\mathrm{D}}$ & $1,94^{\mathrm{CD}}$ & $2,37^{\mathrm{AB}}$ & $2,15^{\mathrm{BC}}$ & - \\
\hline C.V. (\%) & & & & & & & & \\
\hline
\end{tabular}

Médias seguidas de mesmas letras, minúsculas na coluna e maiúsculas na linha, não diferem pelo teste de Tukey a $5 \%$.

${ }^{1}$ Escala de notas: 1 = baixa incidência; $2=$ média incidência; $3=$ alta incidência; $4=$ altíssima incidência do fungo Helminthosporium.

materiais genéticos resistentes (tabela IV). Falconer (1981) relata que o valor máximo da herdabilidade expressa a proporção da variância fenotípica que é atribuída às diferenças genéticas confundidas com os efeitos ambientais permanentes que atuam nos genótipos. Conforme relatos de Shimoya et al. (2002), esse valor mede o grau de determinação genética da característica e é usualmente mais fácil de ser determinado, pois não exige cruzamentos controlados e estudos com progênies.

Segundo Di Renzo et al. (2000), a variância causada pelo ambiente permanente é uma fonte de erro que reduz a precisão nos estudos genéticos, devendo-se ressaltar que o melhorista sempre procura reduzi-la o máximo possível por meio de um manejo cuidadoso, permitindo, dessa forma, que o valor do coeficiente de repetibilidade tornese o mais próximo da estimativa da herdabilidade. O conhecimento do valor máximo da herdabilidade, no caso de culturas perenes como o capim-elefante, é fundamental, pois é grande o intervalo de tempo que vai do início da experimentação, passando pelas avaliações realizadas por meio de medições sucessivas no mesmo indivíduo, até a seleção de materiais genéticos promissores para uso na forma de capineira e pastagem (Diz e Schank, 1995).

O coeficiente de repetibilidade estimado pelo método da análise de variância foi 0,75 (tabela VI). Segundo Daher et al. (2004), 
Tabela VI. Estimativas dos coeficientes de repetibilidade ( $r$ ) e coeficientes de determinação $\left(R^{2}\right)$ da variável ocorrência de mancha ocular, em 16 genótipos de Pennisetum sp., conforme o método de avaliação. (Estimate of the repeatability coefficients $(r)$ and determination coefficients $\left(R^{2}\right)$ of the variable leaf spot ocurrence, in 16 Pennisetum sp. genotypes, according to the evaluation method).

\begin{tabular}{lcc}
\hline Método & $r$ & $R^{2}$ \\
\hline Análise de variância & 0,75 & 0,95 \\
Componente principal, correlação & 0,75 & 0,95 \\
Componente principal, covariância & 0,78 & 0,96 \\
Análise estrutural, correlação & 0,75 & 0,95 \\
\hline
\end{tabular}

este coeficiente é considerado de boa regularidade na repetição dos caracteres de uma etapa de medição para outra, uma vez que a predição do valor real, que é expressa pelo coeficiente de determinação, foi de 0,95 (tabela VI).

Pelo método dos componentes principais, matriz de correlação, as estimativas dos coeficientes de repetibilidade (r) e determinação $\left(\mathrm{R}^{2}\right)$, considerando sete medições (avaliações), foram respectivamente 0,75 e 0,95 (tabela VI). Esses valores para os coeficientes de repetibilidade podem ser considerados altos (acima de 0,70 ), conforme relatado por Farias Neto et al. (2004). Tal fato permite que o melhorista se baseie nessas sete avaliações para identificação de genótipos mais resistentes a helmintosporiose.

Com a utilização do método dos componentes principais - matriz de covariância, as estimativas dos coeficientes de repetibilidade (r) e determinação $\left(\mathrm{R}^{2}\right)$, considerando sete medições, foram respectivamente 0,78 e 0,96 (tabela VI), confirmando que a matriz de covariância possui qualidade para estudo desses coeficientes.

O método da análise estrutural - matriz de correlação, proposto por Mansour et al. (1981), apresenta apenas diferenças conceituais em relação ao dos componentes principais. A estimativa do coeficiente de repetibilidade foi obtida pela média aritmética das correlações fenotípicas entre os genótipos, considerando cada par de medições. As estimativas dos coeficientes de repetibilidade $(\mathrm{r})$ e determinação $\left(\mathrm{R}^{2}\right)$, foram respectivamente 0,75 e 0,95 (tabela VI). Da mesma forma, Shimoya et al. (2002), trabalhando com genótipos de capim-elefante, não encontraram diferenças notórias em relação às estimativas de repetibilidade geradas pelos métodos citados anteriormente.

Os coeficientes de determinação, que demonstram a confiabilidade do valor fenotípico em predizer o valor real dos genótipos, apresentam valores médios superiores a $95 \%$ para a característica avaliada. Estes valores de confiabilidade são referenciados como elevados, uma vez que, segundo Resende (2002), quando se seleciona um grupo de indivíduos, valores acima de $80 \%$ já podem ser considerados adequados.

O número de medições realizadas para a variável mancha ocular foi suficiente para atingir o coeficiente de determinação de

Tabela VII. Número de medições da característica mancha ocular, obtidos de dados de 16 genótipos de Pennisetum sp., associados a diferentes graus de determinação do valor genotípico $\left(R^{2}\right)$, conforme o método. (Number of measurements of the characteristic leaf spot ocurrence, obtained from data of 16 Pennisetum sp. genotypes, associated to different degrees of determination of the genotypic value $\left(R^{2}\right)$, according to methods).

\begin{tabular}{lcc}
\hline Método & $\begin{array}{c}\mathrm{R}^{2} \\
\text { estimado }\end{array}$ & $\begin{array}{c}\text { Número de } \\
\text { medições }\end{array}$ \\
\hline Análise de variância & 0,95 & 6,0 \\
CPcr & 0,95 & 6,0 \\
CPcv & 0,96 & 5,0 \\
AEcr & 0,95 & 6,0 \\
\hline
\end{tabular}

CPcr: Componente principal (correlação); CPcv: Componente principal (covariância); AEcr: Análise estrutural (correlação). 
0,95 (tabela VII), indicando que de acordo com as sete medições realizadas, pode-se predizer o valor dos genótipos com $95 \%$ de confiabilidade, assim, segundo SouzaSobrinho et al. (2004), algumas etapas dos programas de melhoramento tornam-se mais ágeis, contribuindo para um processo mais dinâmico e aumentando as chances de êxito. Para Ferreira et al. (2005), o conhecimento do número suficiente de medições que devem ser realizadas, é importante, pois permite obter estimativas confiáveis, mínimo de custo e redução no emprego de mãode-obra. Silva (2006) encontrou número de medições necessárias variando de 2 a 27 para a variável susceptibilidade a doenças, avaliando diferentes tipos de progênies de Pennisetum.

As estimativas dos coeficientes de repetibilidade para a mancha ocular nos genótipos de Pennisetum foi de 0,75 nos métodos avaliados, exceto para o método da análise do componente principal pela matriz de covariância que foi de 0,78 . Esses resultados indicam que se pode ter confiabilidade na identificação dos melhores valores genotípicos a partir da análise das medidas fenotípicas obtidas. Silva (2006), avaliando descritores morfológicos na seleção de clones de Pennisetum, observou valores de coeficiente de repetibilidade variando de 0 a 1, em diferentes famílias, utilizando o método da análise de variância. Foi observado que as famílias apresentaram comportamento diferenciado com relação à susceptibilidade à doenças, pois o $\mathrm{R}^{2}$ variou de $0 \mathrm{a}$ 0,98 .

Pereira et al. (1998), estimando coeficiente de repetibilidade em genótipos de alfafa, encontraram valores superiores a 0,6 para a variável mancha foliar amarela. Os referidos autores relatam que a predição do valor real, com valores de repetibilidade dessa magnitude, é superior a $90 \%$, indicando que a superioridade ou inferioridade do comportamento das populações nos sucessivos cortes é, relativamente, mantida inalterada.
No presente estudo, a realização de medições adicionais pode ser dispensada, visto que, conforme o número de avaliações de acordo com os coeficientes de determinação pré-estabelecidos por Cruz e Regazzi (1997), seriam suficientes para a característica mancha ocular entre cinco e seis avaliações (tabela VII). Souza-Sobrinho et al. (2004) relatam que a possibilidade de redução no número de avaliações e do tempo exigido para a seleção dos genótipos promissores, contribui substancialmente para a orientação dos programas de melhoramento.

Para a característica estudada, qualquer uma das metodologias, considerando as sete medições (avaliações), foi suficiente para que o processo de seleção realizado tenha $95 \%$ de confiabilidade, e para que o comportamento de superioridade ou inferioridade dos genótipos seja mantido. Pode-se observar que os valores dos coeficientes de determinação $\left(\mathrm{R}^{2}\right)$ são muito próximos (tabela VI). De modo geral, as estimativas de repetibilidade obtidas pelas diferentes metodologias apresentaram boa concordância, mostrando a confiabilidade dos resultados.

Vale ressaltar a importância da estimativa do coeficiente de repetibilidade de um caráter, visto que as avaliações repetidas permitem quantificar a variância fenotípica, a qual poderá ser parcelada, servindo para avaliar o ganho em precisão, pela repetição das medidas, e esclarecer a natureza da variação causada pelo ambiente (Pereira $e t$ al., 2002). Assim, a repetibilidade constitui uma ferramenta indispensável para auxiliar o processo de seleção realizado pelo melhorista de forrageiras.

\section{CONCLUSÕES}

As estimativas dos coeficientes de repetibilidade obtidas pelos métodos de análise de variância, componentes principais, matriz de correlação e matriz de covariância e análise estrutural apresentam 


\section{COEFICIENTES DE REPETIBILIDADE PARA MANCHA FOLIAR EM PENNISETUM}

valores de magnitude semelhantes.

A estimativa de repetibilidade para a característica mancha ocular é superior a 0,75 , demonstrando regularidade do desempenho dos genótipos de Pennisetum sob pastejo nas várias medições (avaliações) e confiabilidade na discriminação genotípica superior a $95 \%$.

Sete medições (avaliações) foram suficientes para obter um coeficiente de

\section{BIBLIOGRAFIA}

Anjos, J.R.N., Charchar, M.J.A., Teixeira, R.N. e Anjos, S.N. 2004. Ocorrência de Bipolaris maydis causando mancha foliar em Paspalum atratum cv. Pojuca no Brasil. Fitop. Bras., 29: 656-66.

Costa, J.G. 2003. Estimativas de repetibilidade de alguns caracteres de produção em mangueira. Ciênc. Rural, 33: 263-266.

CPRH. 2003. Companhia Pernambucana do Meio Ambiente. Diagnóstico sócio ambiental do litoral norte de Pernambuco. Recife. 214 pp.

Cruz, C.D. 2004. Programa GENES: aplicativo computacional em genética e estatística. UFV Viçosa.

Cruz, C.D. e Regazzi, A.J. 1997. Modelos biométricos aplicados ao melhoramento genético. $2^{\mathrm{a}}$ ed. UFV. Viçosa. $390 \mathrm{pp}$.

Cruz, C.D. e Regazzi, A.J. 2001. Modelos biométricos aplicados ao melhoramento genético. UFV. Imprensa Universitária. Viçosa. 390 pp.

Cargnelutti Filho, A., Castilhos, Z.M.S., Storck, L. e Savian, J.F. 2004. Análise de repetibilidade de caracteres forrageiros de genótipos de Panicum maximum, avaliados com e sem restrição solar. Ciênc. Rur., 34: 723-729.

Daher, R.F., Maldonado, H., Pereira, A.V., Amaral Júnior, A.T., Pereira, M.G., Ferreira, C.F., Ramos, S.R.R., Tardin, F.D. e Silva, M.P. 2004 Estimativas de parâmetros de repetibilidade de caracteres forrageiros em clones de capimelefante (Pennisetum purpureum Schum.). Acta Scient. Agron., 26: 483-490.

Di Renzo, M.A., Ibanez, M.A., Bonamico, N.C. and Poverene, M.M. 2000. Estimation of repeatability and phenotic correlations in Eragrostis curvula. J. Agric. Scien., 134: 207-212. determinação de 0,95 pelos quatro métodos utilizados.

\section{AGRADECIMENTOS}

Ao Prof. Rildo Sartori do Laboratório de Fitossanidade da UFRPE, pela ajuda na identificação do fungo no material vegetal e aos funcionários do Campo Experimental de Itambé, pela ajuda na conduçao do experimento.

Diz, D.A. and Schank, S.C. 1995. Heritabilities, genetic parameters, and response to selection in pearl millet x elephantgrass hexaploid hybrids. Crop Sci., 35: 95-101.

Falconer, D.S. 1981. Introdução à genética quantitativa. UFV. Imprensa Universitária. Viçosa. 279 pp.

Farias Neto, J.T., Carvalho, J.U. e Muller, C.H. 2004. Estimativas de correlação e repetibilidade para caracteres do fruto de bacurizeiro. Ciênc. Agrotec., 28: 300-305.

Ferreira, A., Barbosa, M.H.P., Cruz, C.D., Hoffmann, H.P., Vieira, M.A.S., Bassinelo, A.I. e Silva, M.F. 2005. Repetibilidade e número de colheitas para seleção de cana-de-açúcar. Pesqui. Agropecu. Bras., 40: 761-767.

Mansour, H., Nordheim, E.V. and Rutledge, J.J. 1981. Estimators of repeatability. Theor. Appl. Genet., 60: 151-156.

Oliveira, T.N., Santos, M.V.F., Lira, M. de A., Mello, A.C.L., Ferreira, R.L.C. e Dubeux Júnior, J.C.B. 2007. Métodos de avaliação de disponibilidade de forragem em clones de Pennisetum sp. sob pastejo. Rev. Bras. Ciên. Agr., 2: 168-173.

Pereira, A.V., Cruz, C.D., Ferreira, R. de P., Botrel, M.A. e Oliveira, J.S. 2002. Influência da estabilização de genótipos de capim-elefante (Pennisetum purpureum Schum.) sobre a estimativa da repetibilidade de características forrageiras. Ciênc. Agrotec., 26: 762-767.

Pereira, A.V., Ferreira, R. de P., Cruz, C.D., Freitas, V.de P.e Oliveira, P.T. 1998. Comportamento da alfafa cv. Crioula de diferentes origens e estimativas dos coeficientes de repetibilidade para caracteres forrageiros. Rev. Bras. Zootecn., 27: 686-690. 


\section{OLIVEIRA, SANTOS, LIRA, MELLO, FERREIRA, LIRA JÚNIOR E SILVA}

Reis, A., Dubeux Júnior, J.C.B., Melo Filho, R.M. e Menezes, M. 1997. Mancha ocular do capimelefante em Pernambuco-Brasil e seleção de variedades com resistência a doença. Summa Phytopath., 23: 231-235.

Resende, M.D.V. 2002. Genética biométrica e estatística no melhoramento de plantas perenes. Embrapa Informação Tecnológica. Brasília. 975 pp.

Rutledge, J.J.A. 1974. Scaling which removes bias of Abeywardena's estimator of repeatability. J. Genet., 61: 247-250.

SAS Institute. 1999. SAS/STAT. User's guide. Version 8. Cary. $1464 \mathrm{pp}$.

Shimoya, A., Pereira, A.V., Ferreira, R. de P., Cruz, C.D. e Carneiro,P.C.S. 2002. Repetibilidade de características forrageiras do capim-elefante.
Sci. Agric., 59: 227-234.

Silva, M.C. 2006. Avaliação de descritores morfológicos e seleção de diferentes tipos de progênies de Pennisetum sp. Tese (Doutorado em Zootecnia). Universidade Federal Rural de Pernambuco. Recife. 78 pp.

Souza-Sobrinho, F. de, Lédo, F.J. da S., Pereira, A.V., Botrel, M.A., Evangelista, A.R. e Viana, M.C.M. 2004. Estimativas de repetibilidade para produção de matéria seca em alfafa. Ciênc. Rural, 34: 531-537.

Valle, C.B. e Souza, F.H.D. 1995. Construindo novas cultivares de gramíneas forrageiras para os cerrados brasileiros. Reunião Anual da Sociedade Brasileira de Zootecnia, 32. Anais... Sociedade Brasileira de Zootecnia. Brasília. pp. 3-7.

Archivos de zootecnia vol. 60, núm. 231, p. 808. 